\title{
Radiofrequency Turbinoplasty in Imidazoline-induced Rhinitis Medicamentosa
}

\author{
SV Manjunatha Rao
}

\section{ABSTRACT}

Aim: To evaluate the efficacy and results of radiofrequency turbinoplasty in patients with rhinitis medicamentosa due to imidazolines like oxymetazoline and xylometazoline.

Study design: This is a prospective, single-blinded, randomized controlled study.

Materials and methods: Study was conducted on 20 patients in a tertiary level center from January 2010 to February 2016. Patients with symptoms and signs of nasal obstruction due to rhinitis medicamentosa were selected. Patients were aged from 16 to 43 years (mean age is 24 years). Twelve were males and eight were females. The duration of use of nasal decongestant drops varied from 3 months to 5 years. The turbinoplasty was performed using the radiofrequency method. Nasal obstruction symptom evaluation (NOSE) questionnaires are used for subjective assessment and nasal endoscopy view score (NES) was used for objective assessment pre- and postoperatively. Follow-up was done at the end of 15 days and 3 months after surgery. The results were statistically analyzed by paired t-test.

Results: The mean NOSE score before procedure was 92. At the 15th postoperative day, mean NOSE score reduced to 1.3 and it further reduced at the 3rd month to 0.5 ( $p<0.001)$, with $99.5 \%$ reduction in subjective symptoms. The mean NES before procedure was 3.95 . On the 15 th day, it was 0.35 and at the end of 3 rd month, it was 0 with $91.1 \%$ reduction in objective evaluation $(p<0.001)$. Results were same on left and right side of nose. No major postoperative complication was observed in patients.

Conclusion: Radiofrequency turbinoplasty technique can be recommended as an effective method in imidazoline-induced rhinitis medicamentosa. It is simple, comfortable, fast relief giving, no repeated steroids, and cost-effective, single-session treatment. Good compliance and cooperation from patients can be obtained with no major complications of the treatment. It allows patients to be managed in the office environment.

Keywords: Imidazoline, Radiofrequency, Rhinitis medicamentosa.

How to cite this article: Rao SVM. Radiofrequency Turbinoplasty in Imidazoline-induced Rhinitis Medicamentosa. Clin Rhinol An Int J 2017;10(2):53-57.

Source of support: Nil

Conflict of interest: None

\section{Professor}

Department of ENT, Basaveshwara Medical College and Hospital, Chitradurga, Karnataka, India

Corresponding Author: SV Manjunatha Rao, Professor Department of ENT, Basaveshwara Medical College and Hospital, Chitradurga, Karnataka, India, Phone: +919620360677 e-mail: mrsarvade77@gmail.com

\section{INTRODUCTION}

Rhinitis medicamentosa is an adverse nasal congestion induced by overuse of nasal decongestants. ${ }^{1-7}$ Oral medications like antihypertensive, antipsychotics, $\beta$-adrenoceptor antagonists, and oral contraceptives also cause nasal congestion. ${ }^{5,6}$ However, the mechanism by which topical nasal decongestants and oral medications cause nasal congestion differs. ${ }^{2,3}$ Since the first nasal vasoconstrictor ephedrine was isolated in 1887 , these medications have been used in the nose. ${ }^{1,2,7}$ Lake coined the term rhinitis medicamentosa in 1946. ${ }^{1-3,7,8}$ Rhinitis medicamentosa is characterized by nasal congestion without rhinorrhea, postnasal drip, or sneezing that begins after using a nasal decongestant for more than 3 days. ${ }^{2}$

There are two classes of nasal decongestants: Sympathomimetic amines like phenylephrine and pseudoephedrine and imidazolines like oxymetazoline and xylometazoline. ${ }^{1,7}$ The exact pathophysiology of rhinitis medicamentosa is unknown. The imidazolines appear to act postsynaptically on sympathetic nerves and cause vasoconstriction by secreting endogenous norepinephrine via a negative feedback mechanism, thus decreasing blood flow and decongesting the nose. But later on, tolerance develops. The patient becomes increasingly dependent on the drug, and a vicious circle is established that may result in drug habituation. $3,7,8$

Very few prospective studies of rhinitis medicamentosa have been performed and most of the knowledge about the condition comes from case reports and histologic studies. In many subjects, rhinitis medicamentosa occurs after they begin using nasal decongestants to treat other nasal conditions. It is difficult to determine if the rebound congestion is secondary to the initial nasal condition, rhinitis medicamentosa, or both. The validated criteria to diagnose the rhinitis medicamentosa do not yet exist. ${ }^{2}$

The first criteria for the diagnosis of rhinitis medicamentosa were proposed in 1952 and included

- History of prolonged nasal medication,

- Constant nasal obstruction, and

- Poor shrinkage of nasal mucous membranes to local sympathomimetic drugs. ${ }^{2,7}$

It has also been shown that the long-term use of the preservative benzalkonium chloride (BKC), a quaternary 
ammonium compound, in nasal spray accentuates the severity of rhinitis medicamentosa in healthy volunteers. ${ }^{3}$ Benzalkonium chloride alone induces mucosal swelling after 30 days of use of the nasal spray in healthy subjects, unlike placebo. 3,9 The preservative BKC also has a bactericidal effect, because it damages the cell wall of the microorganisms. ${ }^{3}$

Intranasal glucocorticosteroids have been used for the treatment of rhinitis medicamentosa. ${ }^{2,3}$ It was shown in both human and animal models that nasal corticosteroids decrease nasal edema, inflammation, congestion, and nasal edema associated with rhinitis medicamentosa. ${ }^{2,10}$ However, none of the trials had sufficient power and it is questionable in all the studies whether the subjects actually had rhinitis medicamentosa. ${ }^{2}$ No randomized controlled trials are available to prove the usefulness of glucocorticosteroid injections, oral glucocorticosteroids, or oral antihistamines. ${ }^{2}$ Nasal congestion in subjects with presumed rhinitis medicamentosa may not only be caused by the implicated nasal decongestant but may instead be caused or worsened by a concomitant condition, such as allergic rhinitis, nonallergic rhinitis, or other nasal pathology. ${ }^{2}$

Nowadays, radiofrequency (RF) methods are widely used in otorhinolaryngology. ${ }^{11}$ Radiofrequency creates ion excitation in the target tissue cells, causing the temperature to be in the range 60 to $90^{\circ} \mathrm{C}$ (denaturation protein forms in $49.5^{\circ} \mathrm{C}$ ). ${ }^{11,12}$ The $\mathrm{RF}$ that ranges from 300 to $3,000 \mathrm{kHz}$ has been defined as a medium frequency. ${ }^{13}$ The target site is stably formed with tissue-reduced volume approximately 3 weeks postoperatively. ${ }^{13}$ The studies on the use of RF in cases of rhinitis medicamentosa are very little. Evidence was available only indirectly, in studies of inferior turbinate hypertrophy. Therefore, the study was done to evaluate the efficacy of RF turbinoplasty with respect to the obstructive symptoms and patient satisfaction, and to evaluate the complications of the procedure in patients with rhinitis medicamentosa.

\section{AIM}

To evaluate the efficacy and results of RF turbinoplasty in patients with rhinitis medicamentosa due to imidazolines like oxymetazoline and xylometazoline.

\section{MATERIALS AND METHODS}

\section{Study Subjects}

This is a prospective, single-blinded, randomized study conducted in a tertiary center during January 2010 to February 2016. Ethical clearance was obtained from the ethical committee.
In this clinical study, 20 patients, who presented to the outpatient department of ear, nose and throat (ENT) department, were selected. The patients came with main complaint of nasal obstruction with history of use of imidazoline decongestants (oxymetazoline and xylometazoline) for a period of more than 1 month. Initially, they used to get relieved by imidazoline decongestants and now are not relieved by it.

The complete history was taken, and clinical examination and nasal endoscopy were carried on all patients. Four patients underwent computed tomography scan of paranasal sinuses to rule out sinus pathology. None of the study subjects underwent allergic testing. All available treatment options were discussed with each patient before undergoing the procedure.

\section{Inclusion Criteria}

Patients with history of prolonged use of oxymetazoline and xylometazoline for more than 1 month having

- Constant nasal obstruction

- Lack of response to the application of topical decongestant agents with poor shrinkage of nasal mucous membranes on examination

- On examination, "beefy-red" appearance of nasal mucosa with areas of punctate bleeding

- Patients who refused steroid nasal sprays were only selected

\section{Exclusion Criteria}

- Patients with age less than 15 years (as they may not cooperate for the local anesthesia)

- Patients suffering from rhinorrhea

- Patients with postnasal drip

- Patients with sneezing

- Patients with severe nasal deformities and sinus pathology

- Patients with polyps and previous nasal surgery, previous radiotherapy

- Patients with history of septal or turbinate surgery.

\section{Surgical Technique}

The intervention was performed in ENT department, on an outpatient basis. All patients underwent the procedure under local anesthesia. The head end of the table was elevated to $30^{\circ}$ and the nose was packed with cotton impregnated with $4 \%$ xylocaine topical solution for 10 minutes in each inferior meatus.

Afterward, a 26-gauge one-and-a-half inch needle was used to inject a solution of $2 \mathrm{~mL}$ of $1 \%$ lidocaine in 1:400,000. The active portion of the needle was inserted longitudinally, from an endoscopic view, into the 
Radiofrequency Turbinoplasty in Imidazoline-induced Rhinitis Medicamentosa

Table 1: Postoperative changes in NOSE scores at the end of 15 days

\begin{tabular}{|c|c|c|c|c|c|c|c|c|}
\hline \multirow[b]{2}{*}{ NOSE score } & \multicolumn{2}{|c|}{ Before procedure } & \multicolumn{2}{|c|}{ End of 15 days } & \multirow[b]{2}{*}{ Mean difference } & \multirow[b]{2}{*}{$\%$ Reduction } & \multirow[b]{2}{*}{$t$-value } & \multirow[b]{2}{*}{$p$-value } \\
\hline & Mean & $S D$ & Mean & $S D$ & & & & \\
\hline & 92.0 & 10.1 & 1.3 & 2.8 & 90.7 & 98.6 & 37.18 & $<0.001, \mathrm{HS}$ \\
\hline
\end{tabular}

Paired t-test; SD: Standard deviation; HS: Highly significant

submucosa of the anterior and middle parts of the inferior turbinate and lidocaine injected.

In this procedure, the RF cautery machine with power $2 \mathrm{MHz}$ was used. The device power was placed on 0.5 to $2 \mathrm{MHz}$. The bipolar probe was used until the appearance of whitish blush over inferior turbinate. Cotton dipped in $4 \%$ xylocaine was used for a few seconds to control oozing of blood. No nasal packing was administered. Following the procedure, patients did not receive systemic or topical steroids. Patients were explained that there may be nasal stuffiness following the procedure for 2 to 3 days and it will decrease after that. The patients were advised to take antibiotics and analgesics for 1 week and asked to do isotonic saline nasal douching once daily for 1 week. All patients after the procedure were sent back on the same day and were followed up after 15 days and 3 months after the procedure.

\section{Evaluation}

Nasal obstruction symptom evaluation (NOSE) questionnaires were used for subjective assessment, and nasal endoscopy view scores (NESs) were used for objective assessment at the end of 15 days and 3 months after surgery.

In NOSE scoring, five parameters were included, which are nasal stuffiness, nasal obstruction, troubled breathing through nose, troubled sleeping, and unable to get air through nose during exercise. These are graded as 0 - not a problem, 1 - very mild problem, 2 - moderate problem, 3 - fairly bad problem, 4 - severe problem. The raw score of all five parameters is multiplied by five for calculation purpose and total score is scaled from 0 to 100 .

In NES, discharge, edema, and crusting are considered. Each parameter was graded as absent -0 , mild - 1 , severe - 2. Grading was done for both left and right nasal cavity separately.

\section{Data Analysis}

All statistical analyses were performed using paired $t$-test. The significance of the differences between the outcomes prior to and after the intervention was assessed, and p-values $<0.05$ were considered statistically significant.

\section{RESULTS}

In the present study, 20 patients $(\mathrm{n}=20)$ aged from 16 to 43 were included. The mean age was 24 years. In the present study, 12 were males and 8 were females. All had nasal obstruction preoperatively. The duration of use of nasal drops varied from 3 months to 5 years.

The subjective analysis done by NOSE questionnaire preoperatively showed score of 100 in 12 patients and 80 in 8 patients. The mean and standard deviation (SD) were 92 and 10.1 respectively. The NOSE score at 15 th postoperative day was 0 in 16 patients. Three patients showed score of 5 and one patient showed score of 10 . The mean and SD were 1.3 and 2.8 respectively. The mean difference is 90.7 with $98.6 \%$ reduction ( $t$ value 37.18 and $p$-value $<0.001$ ), which was highly significant (Table 1 ). At the end of 3 months, 19 patients showed score of 0 ; however, one patient showed score of 10 . The mean and SD were 0.5 and 2.2 respectively (Graph 1 ). The mean difference was 91.5 with $99.5 \%$ reduction ( $t$ value 37.56 and $p$ value $<0.001$ ) (Table 2).

The objective analysis was done by NES system. Nasal endoscopic score on right side before procedure was $5 / 6$ in 2 patients, $4 / 6$ in 15 patients, and $3 / 6$ in 3 patients. The mean and SD were 3.95 and 0.51 respectively. At the end of 15th postoperative day, it was $0 / 6$ in 13 patients and $1 / 6$ in 7 patients. The mean and SD were 0.35 and 0.49 respectively, with mean difference of 3.6 and $91.1 \%$ reduction ( $t$ value 23.66 and $p$-value $<0.001$ ) (Table 3 ). After 3 months, it was $0 / 6$ in all 20 patients. The mean and SD were 0 with mean difference of 3.6 and 91.1\% reduction ( $\mathrm{t}$ value 23.66 and $\mathrm{p}$-value $<0.001$ ) (Table 4). Similar NES was obtained on left side before and after procedure (Graph 2). Statistical results are same for both right and left sides of nose, and no statistically significant

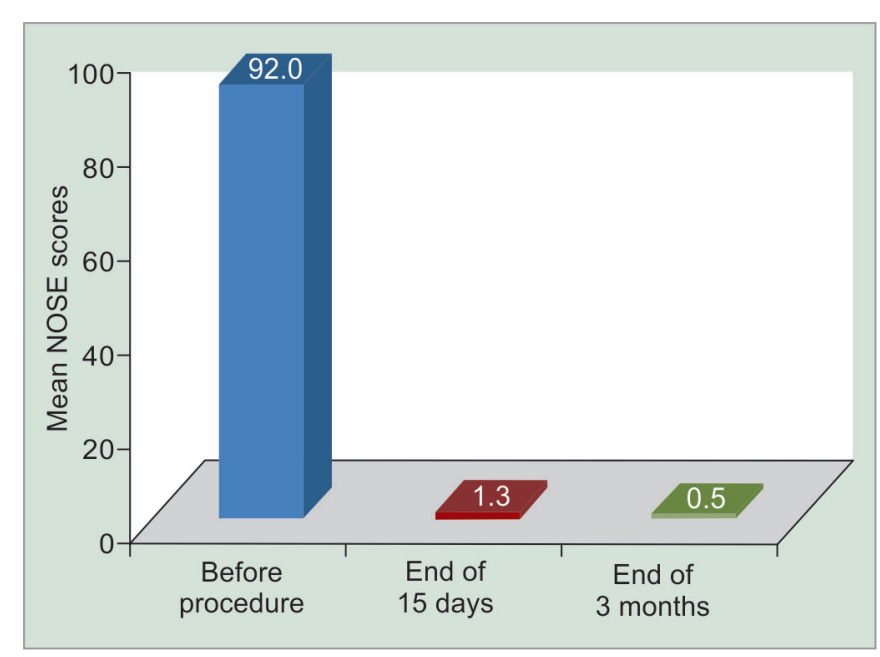

Graph 1: Mean NOSE scores before and after procedure 
Table 2: Postoperative changes in NOSE scores at the end of 3 months

\begin{tabular}{|c|c|c|c|c|c|c|c|c|}
\hline \multirow[b]{2}{*}{ NOSE score } & \multicolumn{2}{|c|}{ Before procedure } & \multicolumn{2}{|c|}{ End of 3 months } & \multirow[b]{2}{*}{ Mean difference } & \multirow[b]{2}{*}{$\%$ Reduction } & \multirow[b]{2}{*}{$t$-value } & \multirow[b]{2}{*}{$p$-value } \\
\hline & Mean & $S D$ & Mean & $S D$ & & & & \\
\hline & 92.0 & 10.1 & 0.5 & 2.2 & 91.5 & 99.5 & 37.56 & $<0.001, \mathrm{HS}$ \\
\hline
\end{tabular}

Paired t-test; SD: Standard deviation; HS: Highly significant

Table 3: Postoperative changes in NES at the end of 15 days

\begin{tabular}{|c|c|c|c|c|c|c|c|c|}
\hline \multirow[b]{2}{*}{ NE score } & \multicolumn{2}{|c|}{ Before procedure } & \multicolumn{2}{|c|}{ End of 15 days } & \multirow[b]{2}{*}{ Mean difference } & \multirow[b]{2}{*}{$\%$ Reduction } & \multirow[b]{2}{*}{$t$-value } & \multirow[b]{2}{*}{$p$-value } \\
\hline & Mean & $S D$ & Mean & $S D$ & & & & \\
\hline & 3.95 & 0.51 & 0.35 & 0.49 & 3.6 & 91.1 & 23.66 & $<0.001, \mathrm{HS}$ \\
\hline
\end{tabular}

Paired t-test; SD: Standard deviation; HS: Highly significant

Table 4: Postoperative changes in NES at the end of 3 months

\begin{tabular}{|c|c|c|c|c|c|c|c|c|}
\hline \multirow[b]{2}{*}{ NE score } & \multicolumn{2}{|c|}{ Before procedure } & \multicolumn{2}{|c|}{ End of 3 months } & \multirow[b]{2}{*}{ Mean difference } & \multirow[b]{2}{*}{$\%$ Reduction } & \multirow[b]{2}{*}{$t$-value } & \multirow[b]{2}{*}{$p$-value } \\
\hline & Mean & $S D$ & Mean & $S D$ & & & & \\
\hline & 3.95 & 0.51 & 0.0 & 0.0 & 3.6 & 91.1 & 23.66 & $<0.001, \mathrm{HS}$ \\
\hline
\end{tabular}

Paired t-test; SD: Standard deviation; HS: Highly significant

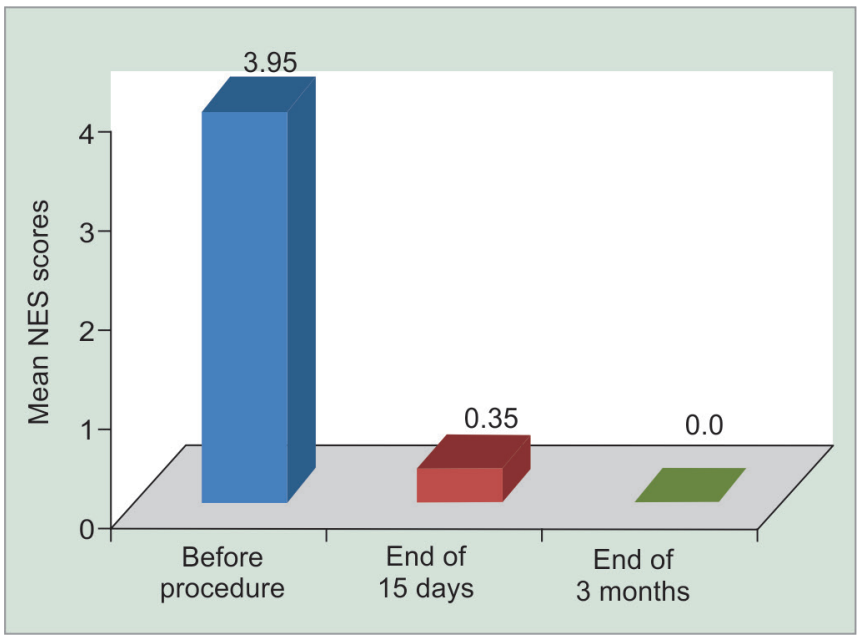

Graph 2: Mean NES scores before and after procedure

difference was observed between the right and left nasal cavity $(\mathrm{p}<0.001)$.

Turbinate edema and secretions decreased significantly at the end of 15 days after the procedure. No adverse reactions, such as reactionary or secondary bleeding, infection, adhesions, synechiae, bone necrosis, and atrophic rhinitis occurred after surgery in all patients.

\section{DISCUSSION}

In India, it has been possible to purchase nose drops containing oxymetazoline and xylometazoline over the counter; there is no need for a doctor's prescription of nasal sprays containing oxymetazoline and xylometazoline. In the present study, out of 20 patients, 17 patients started taking nasal drops for nasal blockage following rhinitis (out of 17, 11 patients were self-medicated), 2 patients in pregnancy, and in 1 patient did not remember the reason. In Toohill et a $1^{14}$ study, out of 130 patients, the major reasons for self-medication were deviated nasal septum in 40 patients, an upper respiratory tract infection in 33 , allergy in 18 , miscellaneous causes in 24 , and unknown in 15 patients.

Rhinitis medicamentosa occurs at a similar rate in men and women, but is more common in young and middle-aged adults. In the present study, the mean age is 24 years, of whom 12 are males and 8 are females. This is in accordance with Ramey et al ${ }^{2}$ study. In Toohill et a ${ }^{14}$ study, 130 patients were included, with 73 males and 57 females, with the peak incidence in young and middle age adults.

Porter et a ${ }^{15}$ reported that $\mathrm{RF}$ is very effective for the improvement of nasal obstructions in a long-term followup of 2 years. The size of the study group was limited to 19 patients. Radiofrequency thermal energy induces an ionic agitation with vaporization at the cellular level in tissues. These processes lead to changes and reduction of volume in tissues during the healing period. ${ }^{11}$ Other surgical methods, such as turbinate cauterization may result in infection, long healing period, mucosal adhesion, and secretion. Radiofrequency procedure is usually well accepted by patients because of low rate of associated complications and high efficiency of the treatment. In the present study, $2 \mathrm{MHz}$ RF is used. In comparison, Akdag et $\mathrm{al}^{13}$ applied 1,050 J. Cukurova et $\mathrm{al}^{16}$ applied 450 to 480 $\mathrm{J}$ for each turbinate. Although different RF energy levels were applied, the results from their study were in support of the present study when compared.

In the present study, two different aspects are evaluated; first, the clinical effectiveness of RF in cases of rhinitis medicamentosa due to imidazolines and second, it compares the results between the right and left nasal cavity. After procedure at the end of 15th day, 16 patients were relieved of the symptom and had no problem. Three 
patients had very mild problem and one patient complained of moderate problem. At the end of 3rd month, 19 patients had no problem and 1 patient had moderate problem. Subjective evaluation shows that RF decreased nasal problem dramatically. In Akdag et al ${ }^{13}$ study, the mean and SD values of NES were 3.96 and 0.20 on both sides before procedure and at the end of 3 months it was 1.02 and 0.75 in right side and 0.84 and 0.74 on left side. Nearly similar statistical results have been obtained in present study. Akdag et $\mathrm{al}^{13}$ showed that RF was equally efficient for both the right and left nasal cavities. Similarly, the present results were in agreement with this finding. In Akdag et a ${ }^{13}$ study, mild congestion and crusting were observed during the first week after the procedure. Crusting symptoms may have originated from the applied amount of RF energy. In the present study, strong correlation between nasal congestion score of patients and anatomical findings was observed and was supported by the obtained NOSE and NES results. A statistically significant relationship between NOSE and NES data during the 3-month period was established.

In Akdag et $\mathrm{al}^{13}$ study at the end of 3 months, $78 \%$ improvement is seen. Cukurova et $\mathrm{al}^{16}$ showed $82 \%$ improvement during 5 years. In the present study, the ratio of improved nasal obstruction was $99 \%$ from pretreatment to 3rd month subjectively and $91 \%$ objectively as the mean values were taken into consideration. Such good results obtained by the RF may be attributed to concurrent treatment of various cofactors, which led to the initiation of use of the nasal decongestant drugs. However, the most important points are permanence and sustainability of the treatment results seen in present study.

In the present study, no major complications are observed. Patients complained of mild pain during the procedure, which was also observed in Sapçi et $\mathrm{al}^{11}$ study. Turbinate edema and secretions were absent at the end of 2 weeks after the procedure. In Akdag et $\mathrm{al}^{13}$ study, no adverse reactions, such as bleeding, infection, adhesions, synechiae, bone necrosis, and atrophic rhinitis were observed in 2-year follow-up. In Saki et al ${ }^{12}$ study, no major complications after RF surgery have been observed at the end of 3 months. In Sapçi et al ${ }^{11}$ study, no major complications were observed.

Finally, the important point of this study was patients' satisfaction with the procedure and abstinence from the steroid sprays. Nasal steroids are not preferred in some conditions because of the inherent risks of administrating them into the nasal cavity and the discomfort associated with their administration. In these set of selective patients, RF can be considered as an alternative therapy. Radiofrequency ablation is such a simple procedure, even in long run; if symptoms recur, the procedure can be easily repeated.

\section{CONCLUSION}

Radiofrequency turbinoplasty technique can be recommended as an effective method in imidazoline-induced rhinitis medicamentosa. It is simple, comfortable, fast relief giving, no repeated steroids, cost-effective, and a singlesession treatment. Good compliance and cooperation from patients can be obtained with no major complications of the treatment. It allows patients to be managed in the office environment. However, since this is a small study, further work needs to be done to determine long-term outcome.

\section{REFERENCES}

1. Black MJ, Remsen KA. Rhinitis medicamentosa. Can Med Assoc J 1980 Apr;122(8):881-883.

2. Ramey JT, Bailen E, Lockey RF. Rhinitis medicamentosa. J Investig Allergol Clin Immunol 2006;16(3):148-155.

3. Graf P. Rhinitis medicamentosa: aspects of pathophysiology and treatment. Allergy 1997 Feb;52(40 Suppl):28-34.

4. Robison JG, Pant H, Ferguson BJ. Rhinitis medicamentosa as a cause of increased intraoperative bleeding. Laryngoscope 2010 Oct;120(10):2106-2107.

5. Garay R. Mechanisms of vasomotor rhinitis. Allergy 2004 Jan; 59(76):4-10.

6. Lekas MD. Rhinitis during pregnancy and rhinitis medicamentosa. Otolaryngol Head Neck Surg 1992 Dec;107(6 Pt 2): 845-848.

7. Scadding GK. Rhinitis medicamentosa. Clin Exp Allergy 1995 May;25(5):391-394.

8. Graf P, Juto JE. Decongestion effect and rebound swelling of the nasal mucosa during 4- week use of oximetazoline. ORL J Otorhinolaryngol Relat Spec 1994 May-Jun;56(3):157-160.

9. Graf $\mathrm{P}, \mathrm{Hallén} H$. Effect on the nasal mucosa of long-term treatment with oxymetazoline, benzalkonium chloride and placebo nasal sprays. Laryngoscope 1996 May;106(5 Pt 1):605-609.

10. Ferguson BJ, Paramaesvaran S, Rubinstein E. A study of the effect of nasal steroid sprays in perennial allergic rhinitis patients with rhinitis medicamentosa. Otolaryngol Head Neck Surg 2001 Sep;125(3):3253-3260.

11. Sapçi T, Güvenç MG, Evcimik MF. Radiofrequency treatment for inferior turbinate hypertrophy. Kulak Burun Bogaz Ihtis Derg 2011 Jan-Feb;21(1):56-60.

12. Saki N, Akhlagh SN, Hekmat-Shoar M, Jafari NS. Efficacy of radiofrequency turbinoplasty for treatment of inferior turbinate hypertrophy. Iran J Otorhinolaryngol 2011 Summer;23(3):87-92.

13. Akdag M, Dasdag S, Ozkurt FE, Celik MY, Degirmenci A, Demir H, Meric F. Long-term effect of radiofrequency turbinoplasty in nasal obstruction. Biotechnol Biotechnol Equip 2014 Mar;28(2):285-294.

14. Toohill RJ, Lehman RH, Grossman TW, Belson TP. Rhinitis medicamentosa. Laryngoscope 1981 Oct;91(10):1614-1621.

15. Porter MW, hales NW, Nease CJ, Krempl GA. Long-term results of inferior turbinate hypertrophy with radiofrequency treatment: a new standard of care. Laryngoscope 2006 Apr;116(4):554-557.

16. Cukurova I, Demirhan E, Cetinkaya EA, Yigitbası OG. Longterm clinical results of radiofrequency tissue volume reduction for inferior turbinate hypertrophy. J Laryngol Otol 2011 Nov;125(11):1148-1151. 